\title{
EFFECTIVENESS ENCHANCEMENT OF HEAT EXCHANGER BY USING NANOFLUIDS
}

\author{
M. Hasanuzzaman ${ }^{\mathrm{a}, \mathrm{b}}$, R. Saidur ${ }^{\mathrm{a}, \mathrm{b}}$ and N.A. Rahim ${ }^{\mathrm{b}}$ \\ ${ }^{a}$ Department of Mechanical Engineering, Faculty of Engineering \\ University of Malaya, 50603 Kuala Lumpur, Malaysia \\ ${ }^{\mathrm{b}}$ Centre of Research UMPEDAC, Level 4, Engineering Tower \\ Faculty of Engineering, University of Malaya, 50603 Kuala Lumpur, Malaysia \\ E-mail: hasan@um.edu.my / hasan.buet99@gmail.com
}

\begin{abstract}
Heat exchanger is the almost common equipment for the industrial process heating. Heat is transferred from one fluid to other fluids by convection and conduction through the wall of the heat exchanger. Effectiveness of heat exchanger depends on the convection heat transfer coefficient of the fluid. Convective heat transfer coefficient of water, $\mathrm{Cu}$-water, Al-water, $\mathrm{Al}_{2} \mathrm{O}_{3}$-water and $\mathrm{TiO}_{2}$-water of $2 \%$ nanoparticle concentration has been calculated for counter flow heat exchanger. It is found that convective heat transfer coefficient of $\mathrm{Cu}$-water, $\mathrm{Al}$-water, $\mathrm{Al}_{2} \mathrm{O}_{3^{-}}$ water and $\mathrm{TiO}_{2}$-water nanofluids are $81 \%, 63 \%, 66 \%$ and $64 \%$ higher compared to pure water respectively. It is found that overall heat transfer coefficient of $\mathrm{Cu}$ water, $\mathrm{Al}$-water, $\mathrm{Al}_{2} \mathrm{O}_{3}$-water and $\mathrm{TiO}_{2}$-water nanofluids are $23 \%, 20 \%, 21 \%$ and $20 \%$ higher compared to pure water respectively.
\end{abstract}

Keywords- Heat Exchanger, Effectiveness, Nanofluid, Thermal conductivity

\section{NOMENCLATURE}

$$
\begin{aligned}
& A=\text { Area }\left(\mathrm{m}^{2}\right) \\
& C_{p}=\text { Specific heat capacity }(\mathrm{kJ} / \mathrm{kg} . \mathrm{K}) \\
& h=\text { Enthalpy }(\mathrm{kJ} / \mathrm{s}) \\
& k=\text { Thermal conductivity }(\mathrm{W} / \mathrm{m} . \mathrm{K}) \\
& L=\text { Length }(\mathrm{m}) \\
& m=\text { Mass flow rate of air }(\mathrm{kg} / \mathrm{s}) \\
& N u=\text { Nusselt number } \\
& \operatorname{Pr}=\text { Prandtl number } \\
& \dot{Q}=\text { Rate of heat transfer }(\mathrm{kJ} / \mathrm{s}) \\
& r=\text { Radius }(\mathrm{m}) \\
& R=\text { Resistance } \\
& \operatorname{Re}=\text { Reynolds number } \\
& T=\text { Temperature }(\mathrm{K}) \\
& \Delta T=\text { Temperature difference }(\mathrm{K}) \\
& U=\text { Overall } \\
& \dot{X}_{\text {destroyed }}=\text { Rate of energy destruction }(\mathrm{kJ} / \mathrm{s}) \\
& \dot{X}_{\text {in }}=\text { Rate of energy input }(\mathrm{kJ} / \mathrm{s}) \\
& \dot{X}_{\text {out }}=\text { Rate of energy output }(\mathrm{kJ} / \mathrm{s})
\end{aligned}
$$

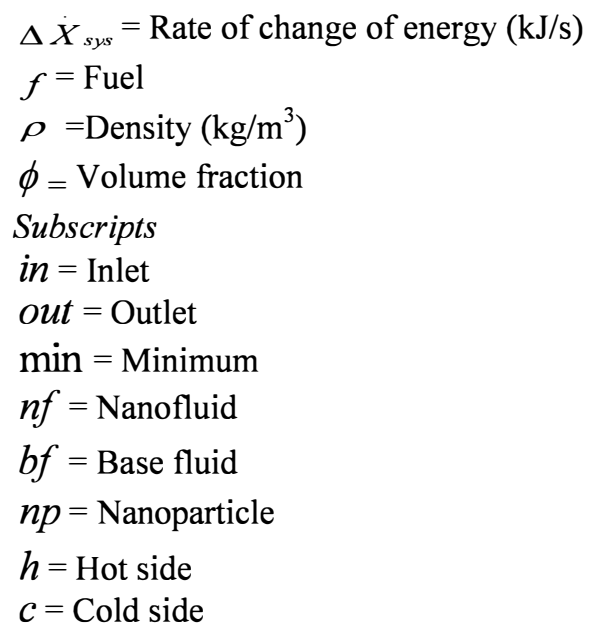

\section{INTRODUCTION}

Energy conservation is a key goal of the world economy and will continue to be one in the future. The most effective way to reduce energy demand is to use energy more efficiently. Heat exchangers are used to transfer thermal energy between two or more media and widely applied to power engineering, petroleum refineries, chemical industries, food industries and so on $[1,2]$. Working fluid selection is one of most important factor of the effectiveness of heat exchanger. At the ambient temperatures, thermal conductivity of metallic solids is an order-of-magnitude higher than fluids (i.e. thermal conductivity of copper is about 700 and 3000 times greater than water and engine oil respectively) that is shown in Figure 1. The heat transfer coefficients of nanofluids are much better than base fluid with little or without pressure drop penalty. The main reasons of heat transfer enhancement of nanofluids as: the suspended nanoparticles increase the thermal conductivity of the fluids, and the chaotic movement of ultrafine particles increases fluctuation and turbulence of the fluids to accelerate exchange heat in the process [4]. Effectiveness of the heat exchanger depends on the thermal conductivity and convective heat transfer coefficient of the fluid. The convective heat transfer coefficient of nanofluids depends on the thermal conductivity, density, specific heat, and viscosity of the nanofluids [5]. Table 1 shows thermophysical properties of water and some nanofluid. 


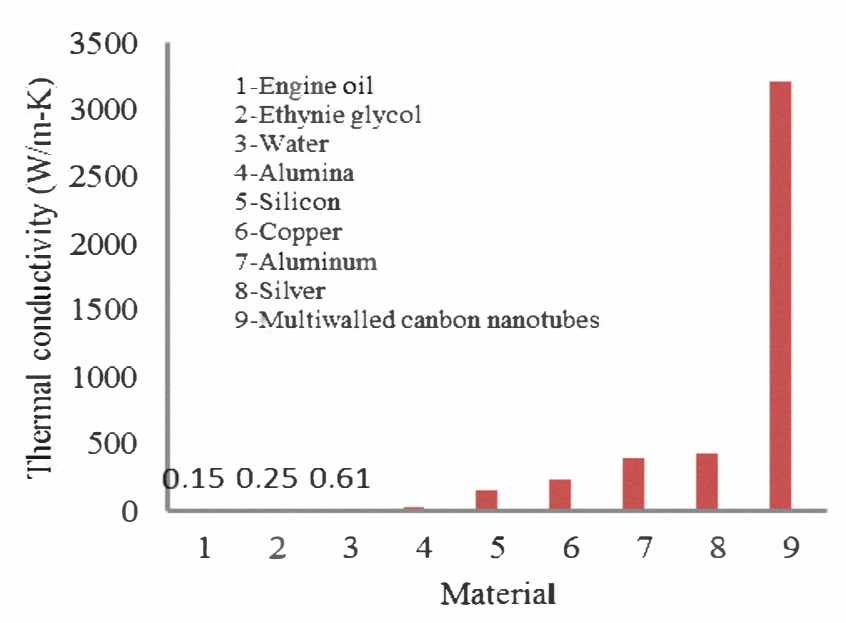

Figure 1 Thermal conductivities of solids and liquids materials at $300 \mathrm{~K}$ [3]

TABLE 1 THERMAL PROPERTY OF WATER \& NANOFLUIDS AT 343K [6]

\begin{tabular}{|c|c|c|c|c|}
\hline Fluids & $\begin{array}{c}\mathrm{k}(\mathrm{W} / \\
\mathrm{m} . \mathrm{K})\end{array}$ & $\begin{array}{c}\rho(\mathrm{kg} / \\
\left.\mathrm{m}^{3}\right)\end{array}$ & $\begin{array}{c}\mu \times 10^{4} \\
(\mathrm{~kg} / \mathrm{m} . \mathrm{s})\end{array}$ & $\begin{array}{c}\mathrm{Cp}(\mathrm{kJ} / \\
\mathrm{kg} . \mathrm{K})\end{array}$ \\
\hline Water & 0.663 & 977.5 & 4.040 & 4.190 \\
\hline Cu-water & 0.749 & 1136.7 & 4.271 & 4.111 \\
\hline $\mathrm{Al}$-water & 0.749 & 1012.3 & 4.271 & 4.121 \\
\hline $\mathrm{Al}_{2} \mathrm{O}_{3}$-water & 0.744 & 1037.4 & 4.271 & 4.119 \\
\hline $\mathrm{Ti}_{2} \mathrm{O}$-water & 0.730 & 1034.9 & 4.271 & 4.117 \\
\hline
\end{tabular}

Thirumarimurugan et al. [7] investigated the effectiveness of heat exchanger by varying mass flow rate of cold fluids in the same heat exchanger. The author found that the effectiveness of the heat exchanger increased from $74.8 \%$ to $87.6 \%$ by changing mass flow rate of cold fluid (i.e. cold water) increased from $118.8 \mathrm{~kg} / \mathrm{h}$ to $656.9 \mathrm{~kg} / \mathrm{h}$ when hot fluid mass flow rate average $51.2 \mathrm{~kg} / \mathrm{h}$. They also investigated the effectiveness of the heat exchanger increased from $53.0 \%$ to $74.1 \%$ by changing mass flow rate of cold fluid (i.e. $10 \%$ acetic acid water solution) increased from $120.2 \mathrm{~kg} / \mathrm{h}$ to $664.1 \mathrm{~kg} / \mathrm{h}$ when hot fluid mass flow rate average $97.6 \mathrm{~kg} / \mathrm{h}$. From the discussion and literature review, it is found that very little work on the application of nanofluids to enhance the effectiveness of heat exchanger. This paper emphasized the potential benefit of using nanofluids to increase the effectiveness of a heat exchanger.

\section{THEORETICAL BACKGROUND AND MATHEMATICAL FORMULA}

This section discussed several basic equations and mathematical relations for the effectiveness of energy analysis in the boiler system.
The expression of heat / energy effectiveness $(e)$ of the heat exchanger considered in the present study are based on the following definitions $[2,8]$ :

$$
e=\frac{\text { Actual heat / energy transfer }}{\text { Maximum possible heat / energy transfer }}
$$

Considering the heat transfer rate is the function of fluid mass flow rate and the inlet and outlet temperature different, the function can be written as:

$$
Q=f(m, T)
$$

The heat transfer rates from the hot fluid to cold fluid are calculated by using following Equation [8-12]:

$\dot{Q}_{h}=\dot{m}_{h} C_{p h}\left(T_{h, \text { in }}-T_{h, \text { out }}\right)$

and the rate of heat received by the cold fluid can be calculated:

$$
\dot{Q}_{c}=\dot{m}_{c} C_{p c}\left(T_{c, \text { in }}-T_{c, \text { out }}\right)
$$

In the heat exchanger, maximum heat exchange is occurred when the fluid temperature will be $T_{h, \text { in }}=T_{c, \text { out }}$ or $T_{h, \text { ou }}=T_{c, \text { in }}$ in a constant mass flow rate of the fluids. Maximum heat transfer rate capacity ( $\dot{Q}_{\max }$ ) can be calculated by using the following equation:

$$
Q_{\max }=\left(m C_{p}\right)_{\min }\left(T_{h, \text { in }}-T_{c, \text { in }}\right)
$$

The function of heat exchanger is to exchange heat between two moving fluid streams without mixing. The hot fluid is releasing heat to the cold and the changes of kinetic and potential energy negligible [13]. The energy balance of heat exchanger is shown in Figure 2.

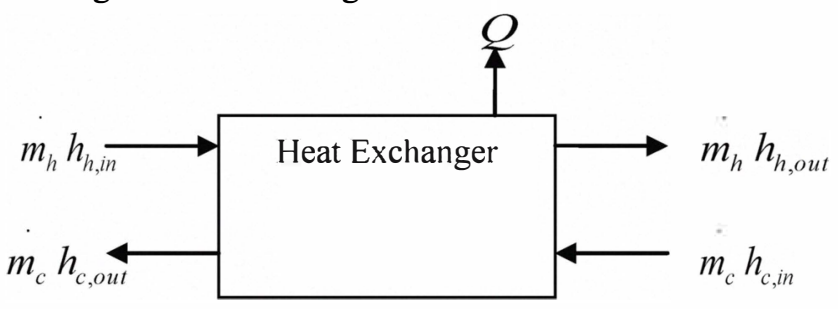

Figure 2 Schematic energy flow diagram of heat exchanger.

In the case of heat exchanger, fluids are not mixed each other due to the wall separating them, the mass flow rate of hot fluids and cold fluid should be constant. Energy balance equation can be expressed as follows [14]:

$$
\begin{aligned}
& X_{\text {in }}-X_{\text {out }}-X_{\text {destroyed }}=\Delta X_{s y s}=0=>\text { steady } \\
& \left(\dot{m}_{h} h_{h, \text { in }}+\dot{m}_{c} h_{c, \text { in }}\right)-\left(\dot{m}_{h} h_{h, \text { out }}+\dot{m}_{c} h_{c, \text { out }}\right)-Q=0 \\
& \dot{m_{h}}\left(h_{h, \text { in }}-h_{h, \text { out }}\right)=\dot{m}_{c}\left(h_{c, \text { out }}-h_{c, \text { in }}\right)+\dot{Q}
\end{aligned}
$$

According to the above assumption and consideration, the effectiveness of the heat exchanger is calculated as follows: 


$$
e=\frac{m\left(h_{\text {out }}-h_{\text {in }}\right)}{m_{\min }\left(h_{h, \text { out }}-h_{c, \text { in }}\right)}
$$

By using the transport properties of the nanofluid, $N u$ number values obtained from the well-known Dittus-Boelter equation in the heat exchanger to relate the heat transfer coefficient [15-18].

$$
N u=0.023 \mathrm{Re}^{0.8} \operatorname{Pr}^{0.4}
$$

The density of nanofluid is determined from equation available in literature $[19,20]$

$$
\rho_{n f}=\phi \rho_{n p}+(1-\phi) \rho_{b f}
$$

Specific heat of nanofluids from equation for estimation of specific heat as $[19,20]$

$$
C_{p, n f}=\phi C_{p, n p}+(1-\phi) C_{p, b f}
$$

Considering a counter flow heat exchanger of hot fluids flowing inside the inner tube and cold fluids flowing outside tube and heat is exchanged in between the fluids. Overall resistance can be expressed as following:

$$
\begin{aligned}
& R_{\text {overall }}=R_{h}+R_{\text {wall }}+R_{c} \\
& \frac{1}{U A_{h}}=\frac{1}{h_{h} A_{h}}+\frac{\ln \left(r_{c} / r_{h}\right)}{2 \pi k L}+\frac{1}{h_{c} A_{c}}
\end{aligned}
$$

If we want to replace the hot fluid by using nanofluids at the same system, so the wall and cold fluid parameter are same as before. Putting as $A=2 \pi r L$ and simplifying the equation (10). In general the convective heat transfer coefficient for water of free convection $20-100 \mathrm{~W} / \mathrm{m} 2 \mathrm{~K}$ and forced convection $50-10,000 \mathrm{~W} / \mathrm{m} 2 \mathrm{~K}$ and $c>1$. From the above equation, it is clear that $U$ will be increased with increasing $h_{h}$. The heat transfer rate of the heat exchanger can be calculated as the following equation:

$$
Q=U A \Delta T
$$

\section{RESULT AND DISCUSSION}

\section{A. Energy effectiveness for the heat exchangers}

In the analysis four heat exchanger of different mass flow rate has been investigated. Figure 3 shows that the effectiveness of heat exchangers varied from $61 \%$ to $68 \%$.

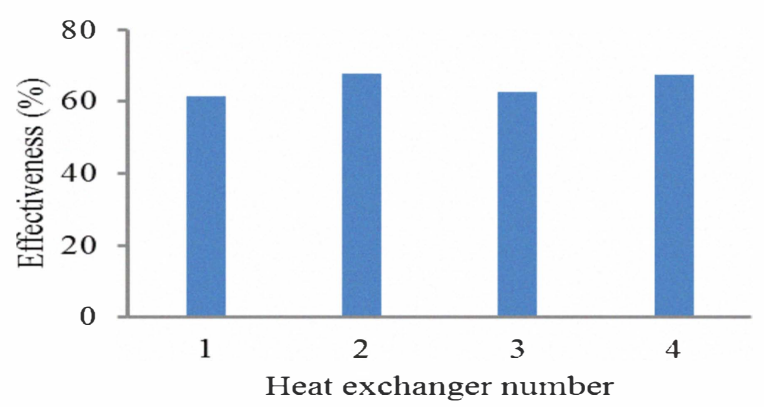

Figure 3 Effectiveness of the counter flow heat exchangers
The author found the effectiveness of the heat transfer varied from $40 \%$ to $92 \%$. It was also found that a great effect of mass flow rate of hot and cold fluids as well as inlet temperature of hot and cold fluids on effectiveness of the heat exchanger.

\section{B. Effectiveness increases of heat exchanger}

Heat exchanger is equipment where the heat exchanges in between two fluids due to the temperatures difference. The heat is transferred by the convection in each fluid and conduction through the wall separating the two fluids. Effectiveness of heat exchanger depends on thermal properties fluids, thermal conductivity of the wall separating the two fluids, type of heat exchanger, etc. Heat transfer rate is directly proportional to the overall heat transfer rate of the heat exchanger. If the convection heat transfer is increased, the overall heat transfer rate also increases. As the convection heat transfer rate is increased with increasing the nanoparticle volume fraction of the nanofluids. Therefore, nanofluids are the potential candidate to increase the heat transfer rate of the heat exchangers. Application of nanoparticles provides an effective way of improving heat transfer characteristics of fluids [21]. By suspending nanoparticles in heating or cooling fluids, the heat transfer performance of the fluid can be significantly improved due to: (a) the nanoparticles increase the surface area, heat capacity and thermal conductivity of the fluids; (b) the interaction and collision among particles, fluid, flow passage surface, mixing fluctuation and turbulence of the fluid are intensified; (c) the dispersion of nanoparticles flattens the transverse temperature gradient of the fluid [22].

\section{Thermal conductivity of nanofluids}

The nanofluids show great potential in enhancing the heat transfer of the process. One reason is that the suspended ultra-fine particles increase the thermal conductivity of the nanofluid [22]. Eastman et al. [21] showed that increase in thermal conductivity of approximately $60 \%$ can be obtained for the nanofluid consisting of water and $5 \mathrm{vol} \% \mathrm{CuO}$ nanoparticles. Xuan and $\mathrm{Li}$ [22] investigated of water $-\mathrm{Cu}$ and found the thermal conductivity of the nanofluid are varied from 1.24 to 1.78 compared to base fluids when the volume fraction of the nanoparticles increases from $2.5 \%$ to $7.5 \%$. The ethylene glycol-CuO nanofluids showed enhancement of more than $20 \%$ at $4 \mathrm{vol} \%$ of nanoparticles [23]. $\mathrm{Al}_{2} \mathrm{O}_{3}$ and $\mathrm{CuO}$ with water about $12 \%$ improvement of the effective thermal conductivity at $3 \mathrm{vol} \%$ of nanoparticles [24]. $\mathrm{Cu}$ in ethylene glycol, $40 \%$ increase in thermal conductivity for only $0.3 \%$ volume fraction of the solid dispersed [25]. Now it is well known that the thermal conductivity of the nanofluids is increased with increasing the volume faction of nano particle. Besides that it is found that, the thermal conductivity is increased with increasing the temperature of the nanofluids. Figure 4 and 5 show thermal conductivity increases with the increase of volume fractions and temperature respectively. 


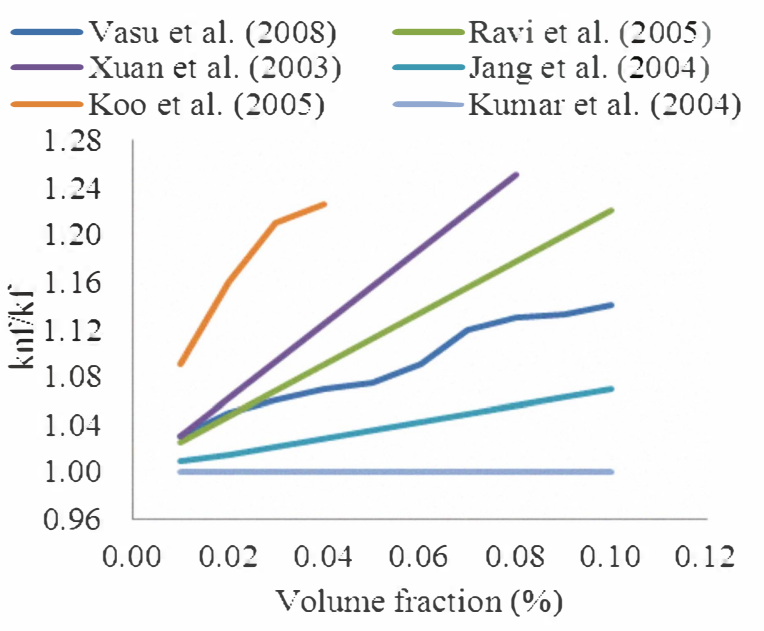

Figure 4 Thermal conductivity augmentations of nanofluids with different nanoparticles volume fraction

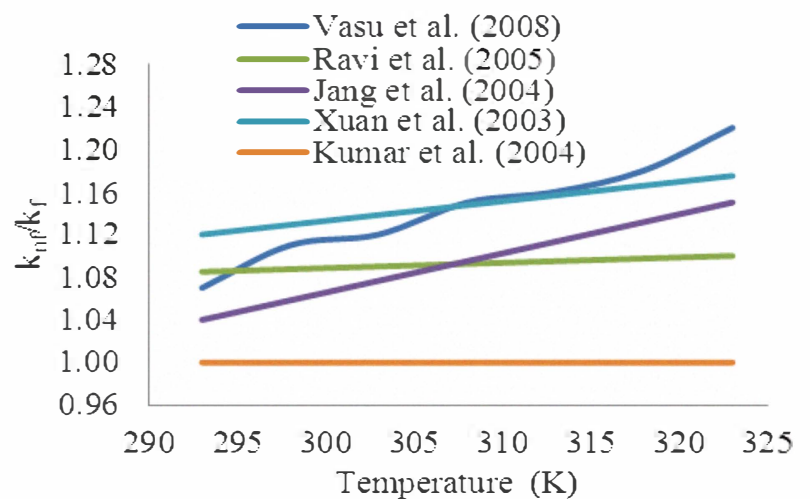

Figure 5 Thermal conductivity variations of nanofluids with different temperature

\section{Convection heat transfer coefficient of nanofluids}

Since thermal conductivity is the most important parameter responsible for enhanced heat transfer many experimental works been reported on this aspect. The researcher found that added nanoparticle in the base fluid is the best option to enhance the thermal conductivity. Convective heat transfer also most important parameter to enhance the heat transfer rate of fluids. Convective heat transfer coefficient of water, $\mathrm{Cu}$-water, $\mathrm{Al}$-water, $\mathrm{Al}_{2} \mathrm{O}_{3}$-water and $\mathrm{TiO}_{2}$-water of $2 \%$ nanoparticle concentration has been calculated for counter flow heat exchanger that is shown in the Figure 6 . It is found that convective heat transfer coefficient of $\mathrm{Cu}$-water, Al-water, $\mathrm{Al}_{2} \mathrm{O}_{3}$-water and $\mathrm{TiO}_{2}$-water nanofluids are $81 \%$, $63 \%, 66 \%$ and $64 \%$ higher compared to pure water respectively. Some experimental works also have been reported on this aspect. It is also found that the heat transfer coefficient increased with increasing the concentration of nanoparticle that is shown in Figure 7. Li and Xuan [18] and $\mathrm{Li}$ and Xuan [26] investigated experimentally the heat convection of nanofluids (i.e. deionized water with $\mathrm{Cu}$ particles) in a tube. The results proved that the nanofluids convective heat transfer coefficient is higher and varied with velocity as well as nanoparticles volume fraction and Nusselt number also $60 \%$ higher with $2 \%$ nanoparticles volume fraction. Yang et al. (2005) experimentally investigated coefficient convective heat transfer in a heat exchanger of horizontal tube and found $22 \%$ higher at 2.5 wt \% fraction of nanoparticle. Heat transfer rate can be increased by using the fluids which thermal conductivity as well as convection heat transfer coefficient is higher. Eastman and Choi [27] reported that the heat transfer coefficient of water containing 0.9 vol.\% of $\mathrm{CuO}$ nanoparticles was improved by $>15 \%$ compared with that of water without nanoparticles. Xuan and Li [18] measured the convective heat transfer coefficient of $\mathrm{Cu}$-water nanofluids in turbulent flow. Their results show that the convective heat transfer coefficient of a nanofluid containing 2.0 vol. \% of $\mathrm{Cu}$ nanoparticles was improved by $>39 \%$ compared with that of water without nanoparticles. In contrast to these studies, Pak and Cho [20] found that the convective heat transfer coefficient of water-based nanofluids with 3 vol.\% $\mathrm{Al}_{2} \mathrm{O}_{3}$ and $\mathrm{TiO}_{2}$ nanoparticles was $12 \%$ smaller than that of pure water when tested under the condition of constant average velocity. Namburu et al. [28] numerically investigated turbulent flow and heat transfer of $\mathrm{CuO}, \mathrm{Al}_{2} \mathrm{O}_{3}$ and $\mathrm{SiO}_{2}$ nanofluids in tube and found Nusselt numbers increases with increasing the nanoparticles volume fraction. It is also found that heat transfer coefficient of $\mathrm{CuO}$ nanofluid is higher compared to other nanofluids.

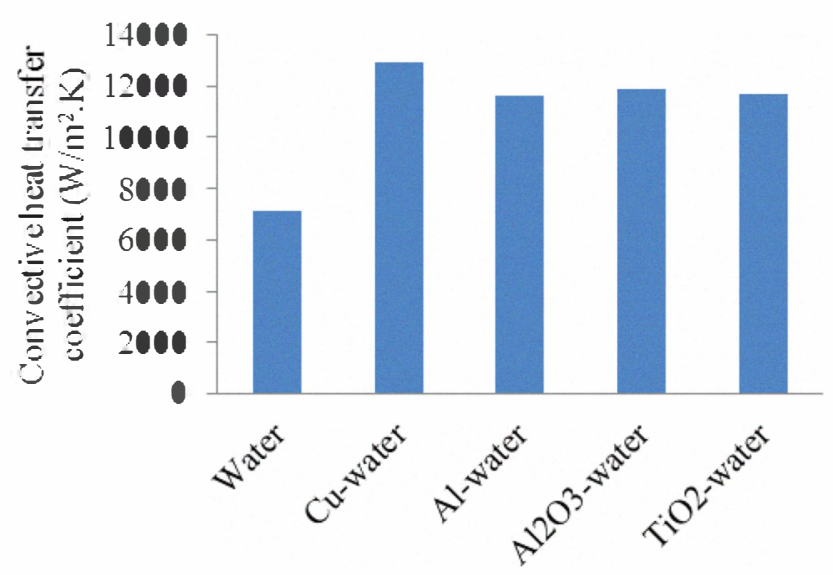

Figure 6 Convection heat transfer coefficient of nanofluids of a heat exchanger

Zeinali et al. [29] experimentally investigated convective heat transfer of $\mathrm{Al}_{2} \mathrm{O}_{3}$-water nanofluids in a circular tube and found increases of a heat transfer coefficients with increasing the nanoparticle. Yu et al. [30] conducted experiments by using silicon carbide nanofluids with $3.7 \%$ volume fraction and found the heat transfer coefficients are $50 \%$ to $60 \%$ higher compared to the base fluids. Kim et al. [31] investigated and found the heat transfer performances in a circular straight tube improved by $15 \%$ and $20 \%$ in laminar and turbulent flow, respectively. 


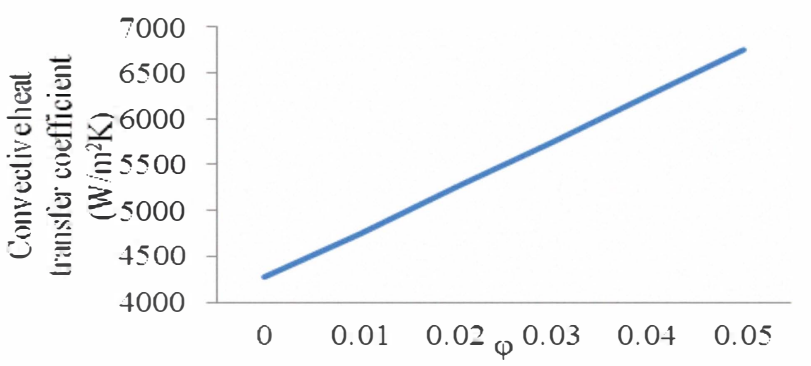

Figure 7 Variation of cylinder liner surface heat-transfer coefficient as nanofluids concentration increases [6]

\section{E. Overall heat transfer coefficient of a heat exchanger by using nanofluids}

Overall heat transfer coefficient of a heat exchanger has been calculated by using the different type of fluids of $2 \%$ nanoparticle concentration that is shown in Figure 8. It is found that overall heat transfer coefficient of $\mathrm{Cu}$-water, $\mathrm{Al}-$ water, $\mathrm{Al} 2 \mathrm{O} 3$-water and $\mathrm{TiO} 2$-water nanofluids are $23 \%$, $20 \%, 21 \%$ and $20 \%$ higher compared to pure water respectively.

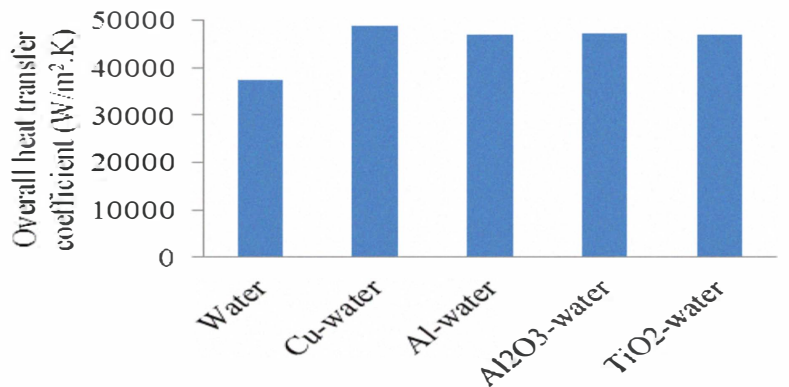

Figure 8 Overall heat transfer coefficient of the counter flow heat exchanger.

Bai et al. [6] investigated cylinder body and found when the $\mathrm{Cu}$ nanoparticles concentration is $5 \%$, the average heat dissipating capacity of the single cylinder is increased by $43.9 \%$ compared with pure water. These show that nanofluids have much stronger heat-transfecr capability than pure water.

\section{F. Losses in the heat exchanger}

Friction effect of nanofluids (i.e. pressure drop) is almost equal to base fluid for the equal flow velocity and does not vary with increasing volume fraction. Therefore, there is no effect of nanofluids (i.e. no penalty) on pumping power [4]. Bai et al. [6] investigated that fluid viscosity increases due to the nanoparticles. There was stronger frictional resistance during the fluid flow in the cooling jacket which is increased the pressure drop. Bai et al. [6] investigated the pump power reduction of an engine cooling system only increased by $6 \%$, which is much less compared with a
$43.9 \%$ increase of the heat dissipating capacity. Consequently, it is acceptable for the price of increasing a little pump power to increase heat-dissipating capacity sufficiently. Leong et al. [16] investigated and analysed of the pressure drop and pumping power for a radiator that is shown in Figures 9 and 10. The pressure drop is increased with increasing nanoparticles. Authors also revealed that pressure drop was $110.97 \mathrm{kPa}$ for $2 \%$ copper nanoparticles compared to $98.93 \mathrm{kPa}$ for the base fluid where the pumping power increases about $12.13 \%$.

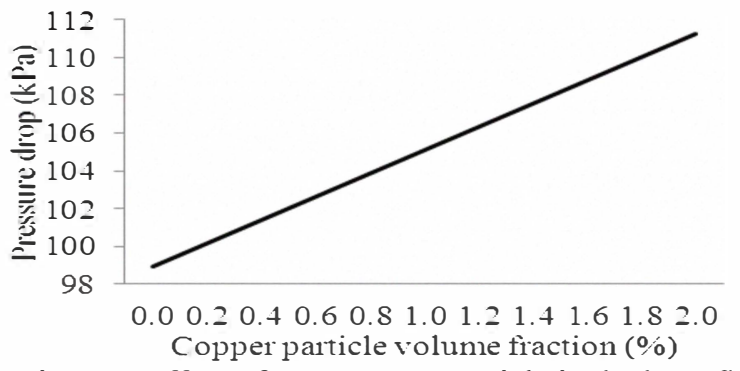

Figure 9 Effect of copper nanoparticle in the base fluid on pressure drop [16]

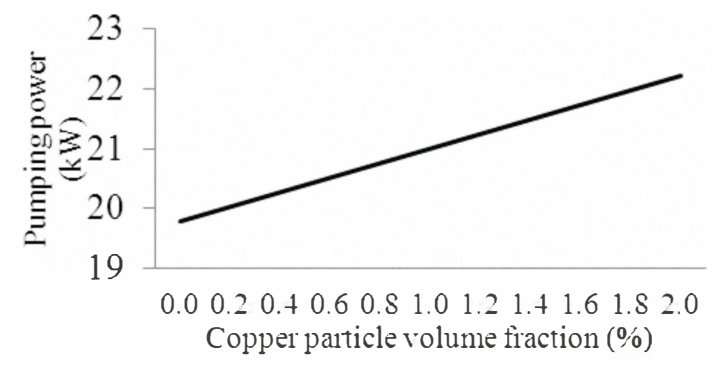

Figure 10 Effect of the copper nanoparticle in the base fluid on pumping power [16]

Because of these effects, a thermodynamic analysis is essential for optimization of heat transfer and pressure drop. However, pressure drop is not so importance for heat exchanger as increasing efficiency that reduces dimensions and decreases production costs [9].

\section{G. Impact and potential benefits of using nanofluids}

The impact and potential benefits of nanofluid technology are expected to be great due to the heat transfer performance of heat exchanging devices. The industrial sector has a need to reduce size and weight of heat exchanging equipment where nanofluids can be the potential candidate [3]. Nanofluid is a great potential option to support the current industrial trend for the component and system miniaturization by supporting the design (i.e. compact and light heat exchanging equipment). Miniaturized heat exchanging equipment reduce the inventory of heat transfer fluid and result in cost savings. Leong et al. [16] investigated a car radiator and estimated $18.7 \%$ reduces the air frontal area by using nanofluid of $2 \%$ copper nanoparticles. The high thermal conductivity of nanofluids 
translates into higher energy efficiency, better performance, reduce energy consumption and lower operating costs. Benefits of heat transfer enhancement of reduce driving potential (i.e. required temperature difference) of the desired output, and reduced pumping power required for the desired output, smaller inventories of fluids, reduce weight and size of the thermal systems [4]. It is clear that nanofluids are the potential candidates for heat transfer enhancement and highly suited for practical application in the heat transfer processes. So, it is a great opportunity for engineers to design high compact and effective heat exchanging equipment [4].

\section{CONCLUSIONS}

In this study, it is found that the energy effectiveness of heat exchangers varied from $61 \%$ to $71 \%$. Convective heat transfer coefficient of $\mathrm{Cu}$-water, $\mathrm{Al}$-water, $\mathrm{Al}_{2} \mathrm{O}_{3}$-water and $\mathrm{TiO}_{2}$-water nanofluids are $81 \%, 63 \%, 66 \%$ and $64 \%$ higher compared to pure water respectively. Overall heat transfer coefficient of $\mathrm{Cu}$-water, Al-water, $\mathrm{Al}_{2} \mathrm{O}_{3}$-water and $\mathrm{TiO}_{2}$ water nanofluids are 23\%, 20\%, 21\% and 20\% higher compared to pure water respectively. It could be concluded that, by using nanofluid the effectiveness of heat exchanger will be increased.

\section{REFERENCES}

[1] M. Hasanuzzaman, N.A. Rahim, R. Saidur and S.N. Kazi, Energy savings and emissions reductions for rewinding and replacement of industrial motor. Energy, 2011. 36(1): pp. 233-240.

[2] R. Saidur, M. Hasanuzzaman, M. A. Sattar, H. H. Masjuki, M. Irfan Anjum and A. K. M. Mohiuddin, An analysis of energy use, energy intensity and emissions at the industrial sector of Malaysia,. International Journal of Mechanical and Materials Engineering, 2007. 2(1): pp. $84-92$.

[[3] S. M. S. Murshed, K. C. Leong, and C. Yang, Thermophysical and electrokinetic properties of nanofluids - A critical review. Applied Thermal Engineering, 2008. 28(17-18): pp. 2109-2125.

[4] W. Daungthongsuk and S. Wongwises, A critical review of convective heat transfer of nanofluids. Renewable and Sustainable Energy Reviews, 2007. 11(5): pp. 797-817.

[5] P. Keblinski, J. A. Eastman, and D. G. Cahill, Nanofluids for thermal transport. Materials Today, 2005. 8(6): pp. 36-44.

[6] M. Bai, Z. Xu, and J. Lv, Application of Nanofluids in Engine Cooling System. SAE International, 2008-01-18, 2008.

[7] M. Thirumarimurugan, T. Kannadasan, and E. Ramasamy, Performance Analysis of Shell and Tube Heat Exchanger Using Miscible System. American Journal of Applied Sciences 2008. 5(5): pp. 548-552.

[8] P. Naphon, Thermal performance and pressure drop of the helical-coil heat exchangers with and without helically crimped fins. International Communications in Heat and Mass Transfer, 2007. 34(3): pp. 321-330.

[9] A. Durmus, et al., Investigation of heat transfer and pressure drop in plate heat exchangers having different surface profiles. International Journal of Heat and Mass Transfer, 2009. 52(5-6): pp. 1451-1457.

[10] S. Eiamsa-ard and P. Promvonge, Enhancement of heat transfer in a tube with regularly-spaced helical tape swirl generators. Solar Energy, 2005. 78(4): pp. 483-494.

[11] M. Hasanuzzaman, R. Saidur, and H. H. Masjuki, Effects of operating variables on heat transfer and energy consumption of a household refrigerator-freezer during closed door operation. Energy, 2009. 34(2): pp. 196-198.
[12] M. Hasanuzzaman, R. Saidur, and H.H. Masjuki, Moisture transfer and energy losses of household refrigerator-freezer during the closed door operation. International Journal of Mechanical and Materials Engineering, 2008. 3(1): pp. 30-37

[13] R. Saidur, J. U. Ahamed, and H. H. Masjuki, Energy, exergy and economic analysis of industrial boilers. Energy Policy, 2010. 38(5): pp. 2188-2197.

[14] M. Hasanuzzaman, R. Saidur and N.A. Rahim, Energy, exergy and economic analysis of an annealing furnace. International Journal of Physical Sciences 2011. 6(6): pp. 1257-1266.

[15] D. Wen and Y. Ding, Experimental investigation into convective heat transfer of nanofluids at the entrance region under laminar flow conditions. International Journal of Heat and Mass Transfer, 2004. 47(24): pp. 5181-5188.

[16] K. Y. Leong, et al., Performance investigation of an automotive car radiator operated with nanofluid-based coolants (nanofluid as a coolant in a radiator). Applied Thermal Engineering, 2010. 30(17-18): pp. 26852692.

[17] V. Vasu, K. R. Krishna, and A. C. S. Kumar, Thermal design analysis of compact heat exchanger using nanofluids. International Journal of Nanomanufacturing, 2008. 2(3): pp. 271-288.

[18] Y. Xuan and Q. Li, Investigation on Convective Heat Transfer and Flow Features of Nanofluids. Journal of Heat Transfer, 2003. 125(1): pp. 151-155.

[19] L. S. Sundar, K. V. Sharma, and S. Ramanathan, Experimental investigation of Heat Transfer Enhancements with $\mathrm{Al} 2 \mathrm{O} 3$ Nanofluid and Twisted Tape Insert in a Circular Tube. International Journal of Nanotechnology and Applications, 2007. 1(2): pp. 21-28.

[20] B. C. Pak and Y. I. Cho, Hydrodynamic and Heat Transfer Study of Dispersed Fluids with Submicron Metallic Oxide Particles. Experimental Heat Transfer, 1998. 11(2): pp. 151-170.

[21] J. A. Eastman, et al., Enhanced thermal conductivity through the development of nanofluids, Nanophase and Nanocomposite Materials II. MRS, Pittsburg, PA. 1997: pp. 3-11.

[22] Y. Xuan and Q. Li, Heat transfer enhancement of nanofluids International Journal of Heat and Fluid Flow, 2000. 21(1): pp. 58-64.

[23] S. Lee, et al., Measuring Thermal Conductivity of Fluids Containing Oxide Nanoparticles. Journal of Heat Transfer 1999. 121: pp. 280-289.

[24] X. Wang, X. Xu, and S. U. S. Choi, Thermal Conductivity of Nanoparticle - Fluid Mixture. Journal of Thermophysics and Heat Transfer 1999. 13(4): pp. 474-480.

[25] J. A. Eastman, et al., Anomalously increased effective thermal conductivities of ethylene glycol-based nanofluids containing copper nanoparticles. Applid Physics Letters 2001. 78(6): pp. 718-720.

[26] Q. Li and Y. Xuan, Convective heat transfer and flow characteristics of Cu-water nanofluid. Science in China (Series E), 2002. 45(4): pp. 408-416.

[27] J. A. Eastman and U. S. Choi, Novel thermal properties of Nanostructured material. Material Science Forum, 312- 314, 1999: p. $629-634$.

[28] P. K. Namburu, et al., Numerical study of turbulent flow and heat transfer characteristics of nanofluids considering variable properties. International Journal of Thermal Sciences, 2009. 48(2): pp. 290-302.

[29] S. Zeinali Heris, M. Nasr Esfahany, and S. G. Etemad, Experimental investigation of convective heat transfer of $\mathrm{Al} 2 \mathrm{O} 3 /$ water nanofluid in circular tube. International Journal of Heat and Fluid Flow, 2007. 28(2): pp. 203-210

[30] W. Yu, D.M France, D.S. Smith, D. Singh, E.V Timofeeva and J.L. Routbort, Heat transfer to a silicon carbide/water nanofluid. International Journal of Heat and Mass Transfer, 2009. 52(15-16): pp. 3606-3612.

[31] D. Kim, Y. Kwon, Y. Cho, C. Li, S. Cheong, Y. Hwang, J. Lee, D. Hong and $\mathrm{S}$. Moon, Convective heat transfer characteristics of nanofluids under laminar and turbulent flow conditions. Current Applied Physics, 2009. 9(2, Supplement 1): pp. e119-e123. 